\title{
Elementos milenaristas na Revolução Russa
}

\author{
GEORGES NIVAT
}

$\mathrm{P}$

ASTERNÁK ESCREVEU que o maior romance russo do século XIX foi o socialismo russo. O poeta tinha em mente não tanto a influência de Karl Marx na Rússia (embora saibamos que $O$ Capital fora vertido para o russo bem antes que para outras línguas), mas o destino do sonho que pairou sobre o horizonte histórico russo no século XIX: a revolução.

A idéia de que a Rússia podia fazer uso do Tempo e da História de modo diverso do da Europa Ocidental aparece com Pedro, o Grande. O salto do atraso para o modernismo exacerbado foi o sonho daquele "primeiro bolchevique", como o denominou Nikolái Berdiáeiv (sem grandes elogios).

O historiador e economista russo-americano Gerschenkron introduziu o conceito de horizonte histórico, que é muito útil para meu presente intento. Qualquer empreendimento humano é concebido, realizado e julgado em algum horizonte histórico, isto é, uma projeção para o futuro das intenções humanas. Investir dinheiro em uma empresa, conquistar um novo território, trazer colonizadores ou especialistas estrangeiros implica uma certa previsão histórica de longo prazo, como a Rússia tinha durante o século XVIII quando começou se a desenvolver industrialmente, receber colonizadores alemães e administrar racionalmente os vastos territórios incorporados pelos seus exércitos. Se se acreditar na proximidade do Apocalipse, no fim dos tempos, não haverá interesse em se investir dinheiro e planejar novos empreendimentos. Contudo, até onde sabemos, uma posição filosófica como a crença de Calvino na predestinação e na completa ignorância quanto aos desígnios de Deus com relação ao ser humano pode ser o impulso para a expansão econômica, como foi demonstrado por Max Weber. De certo modo, os Velhos Crentes da Rússia formam uma variante dessa crença. $\mathrm{O}$ desconhecimento de aspectos sobre começos e fins leva as pessoas a ficarem sozinhas com sua consciência, e as leva a tentar trabalhar de acordo com o que consideram boa conduta.

Existia uma grande diferença entre o horizonte histórico dos romances franceses e o dos russos do século XIX. Balzac mostra-nos heróis ávidos para conquistar a sociedade pelo dinheiro ou pela intriga... Eles acreditam na estabilidade da sociedade o suficiente para tentar conquistá-la e também crêem em uma certa franqueza. Sob esse ponto de vista, Rastignac é o mais típico herói balzaquiano.

O romance russo não nos oferece um Balzac. A concepção de tempo de Gógol está vinculada ao século XVIII, como o romance picaresco de Gil Blas (Tchitchikóv 
é um herói picaresco e a segunda parte de Almas mortas está construída sobre a idéia de uma visão cristã). Gontcharóv é um maravilhoso pintor de um mundo sem tempo - simbolizado pelos habitantes de Oblomóvka, que não têm tanto medo do futuro, já que nunca abrem uma carta, se alguma vez uma carta lhes chega. Tolstói está plenamente ocupado com o drama de heróis que se desviam do tempo cíclico e sempre tenta restabelecer o tempo cíclico em seu ritmo (veja-se o epílogo de Guerra e paz). O único romancista russo profundamente relacionado com a estrutura do futuro é Dostoiévski, mas o Tempo, em sua obra, está sempre em um estado de crise, e ninguém sabe o que acontecerá no próximo minuto, tanto na vida pessoal quanto na social. Os possessos são a mais dramática descrição desse estado de crise.

Daí podermos dizer que o romance russo do século XIX, ao contrário dos romances franceses e ingleses, foi incapaz de mostrar a sociedade em um estado de relativa evolução ou educação. O romance educativo não é um lugar-comum russo (exceto no primeiro romance de Gontcharóv, Uma história ordinária).

Por que existe tanta discrepância? Porque a Literatura Russa no século XIX se desenvolve em um contexto com um horizonte histórico bastante diferente. Há pouco em comum entre a gélida Rússia nikolaievana e a estrutura de crise dos romances de Dostoiévski, ou a nostalgia utópica em Tolstói. O horizonte histórico russo parece ser principalmente místico. No último capítulo da primeira parte de Almas mortas, Gógol revela a seu leitor algo do futuro místico da Rússia, uma tróica russa avançando pelo futuro à frente de nações e povos estupefatos. Os possessos ou $A$ juventude tosca não terminam com uma perspectiva histórica, exceto pelo ideal de ofendidos e humilhados na pessoa de uma pobre mulher que vai de aldeia a aldeia para vender evangelhos.

O principal romance sobre o futuro é $O$ que fazer? de Tchernichévski, o subtítulo do qual é Uma história de um novo povo. O novo povo consiste nos socialistas, e eles sonham com uma outra nova sociedade. Os sonhos didáticos de Vera Pávlova consistem em uma versão exorcizada da utopia cristã. O desenvolvimento de um milênio socialista foi sonhado como um tipo de revelação ou apocalipse.

Daí aquela Rússia estar profundamente dividida entre conservadores do presente, tal qual Karamzín, cuja Observação sobre a velha e a nova Rússia, entregue a Aleksándr I no ano de 1811, em Tver, era uma declaração de fé no conservadorismo por medo do futuro - Quem pode dizer o que é a esperança de longevidade da Rússia? - escrito por um liberal, por um lado; e por sonhadores de uma reviravolta despótica e primordial, como Pestel, por outro. E ainda, na geração seguinte, entre conservadores românticos, como Leôntiev, o apóstolo da Rússia gélida e Tchernichévski, o apóstolo do novo povo.

Como sabemos, a questão polêmica dos socialistas russos versava sobre a velocidade das mudanças, a possibilidade, ou não, de se poder saltar um estágio intermediário natural como a revolução burguesa. Desprezar as leis naturais da evolução pela causa de uma revolução mística foi a idéia fixa dos revolucionários russos. 


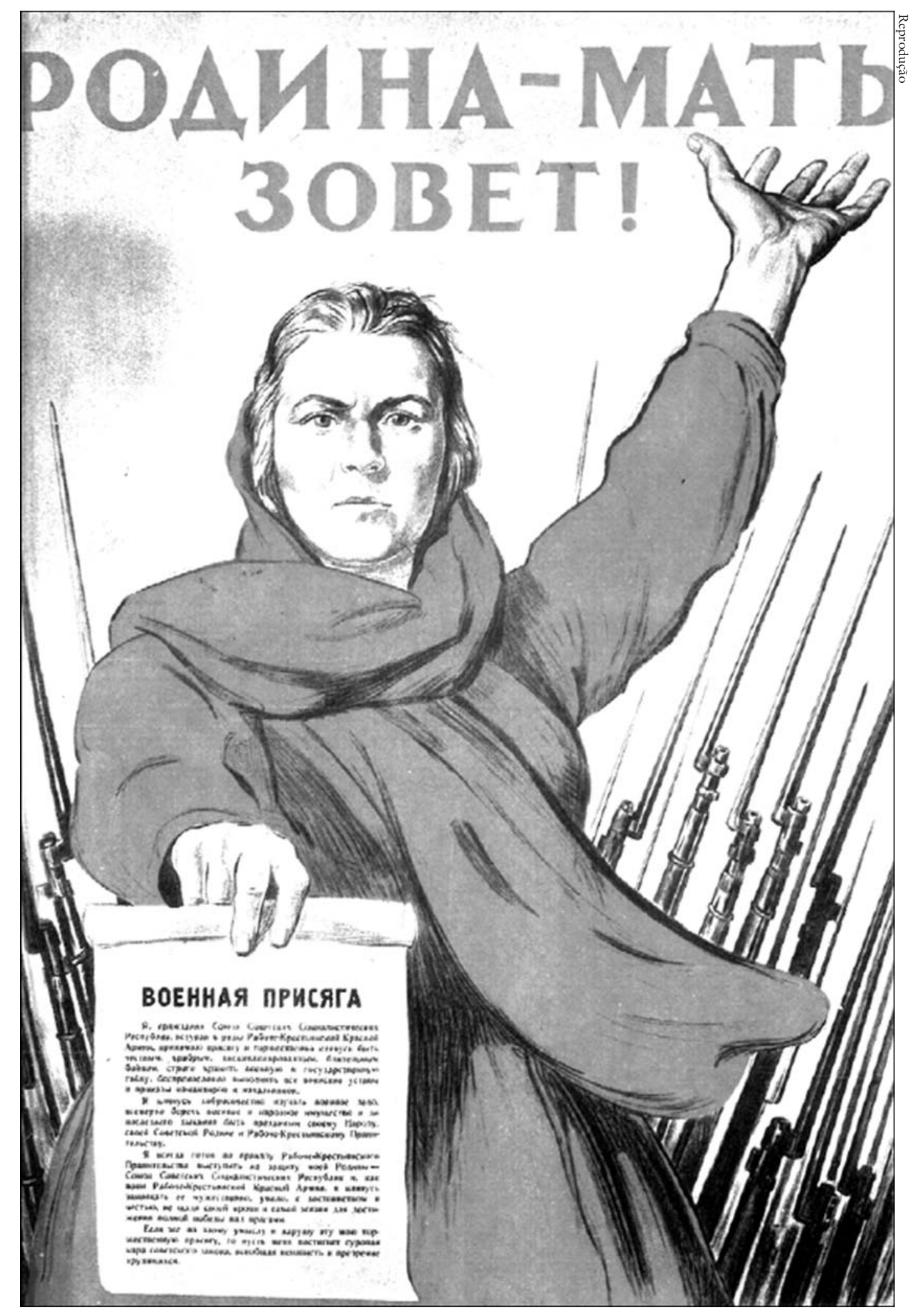

Guerra patriótica: A mãe Pátria conclama! 
Mircea Eliade, em seu Tratado da história das religiões, estabelece uma distinção entre época heterogênea junto aos povos primitivos e época cíclica nos conceitos religiosos. Podemos dizer que o conceito russo de época parece estar dividido entre época utópica e época epiléptica, como ver-se-á em O idiota de Dostoiévski. A época epiléptica é uma sucessão aleatória de crises que não permite uma visão prospectiva na História. A época utópica está inteiramente direcionada para o fim da História e para a idéia de salvação.

Entre as várias polêmicas relativas à inteligentsia russa, por exemplo, ocorreme relembrar a disputa entre Lavrov e Bakúnin sobre a possibilidade de se conhecer o futuro. Lavrov não era marxista, não tinha aquele tipo de esquema simplista sobre o futuro que o socialismo científico e o conceito de luta de classes tinham largamente difundido na Rússia. Mas, Lavrov, o criador de Adiante! (Vperiôd!) pensava que a ciência poderia ajudar a conhecer algo sobre algumas formas de vida futura. Ele considerava os revolucionários como preparadores. Bakúnin, ao contrário, achava que os revolucionários não tinham nada a preparar: eles simplesmente destruíam, já que essa é a vocação do anarquismo. Para Bakúnin, Marx foi um típico pangermanista e criador de um número cada vez maior de Estados. A periferia da Europa estava supostamente opondo-se à grande onda de estatismo pangermanista: a Espanha, o Sul da Itália, a Jura suíça e a Rússia. No seu famoso Apêndice $A$ ao livro Estado e anarquia, Bakúnin nega a possibilidade de a ciência descobrir qualquer coisa sobre as formas de vida futura. Nem podem a educação, a cooperação ou alguma outra ação da inteligentsia mudar o povo.

Essa disputa entre anarquismo e populismo é, no mínimo, tão significativa quanto a bem conhecida discussão entre populistas e marxistas, que foi sintetizada no famoso livro de Plekhánov Nossas diferenças. O pensamento russo, influenciado por Hegel, Marx, Feuerbach e Mach discutiu continuamente o problema do dilema entre ação e necessidade, liberdade criativa e leis do progresso. O pensamento de Bogdánov, por exemplo, um seguidor de Mach, autor de Tecnologia (1922) e inspirador do bogostroítielstvo, influenciou profundamente Górki, quando este escreveu As confissões (1909). O problema não é interpretar o mundo e sim, transformá-lo.

Assim, enquanto alguns autores queriam educar o povo e deixar que ele se desenvolvesse sem interferências, como Lavrov, ou pensavam que se pudesse tão somente destruir um mundo ruim e fazer com que uma nova vida emergisse livremente depois dele, como Bakúnin, ou que se devesse restaurar a razão da História, como Plekhánov, ou ainda tentar restabelecer o grande equilíbrio de estruturas, como Bogdánov - o pensamento russo desenvolvia-se exclusivamente em torno da idéia do futuro. A imaturidade russa, a juventude da Rússia, eram vistas como uma prova de que ela era o melhor laboratório para o futuro.

Como sabemos, Lênin leria Hegel, rejeitando Deus (bôjenka, um diminutivo depreciativo para a palavra Deus), isto é, o Absoluto. Seu interesse principal era e sempre esteve relacionado com a flexibilidade do futuro: "A flexibilidade multilateral e universal dos conceitos, uma flexibilidade que atinge a identidade dos 
opostos, este é o cerne da questão. A flexibilidade aplicada subjetivamente redunda no ecletismo e no raciocínio sofístico. A flexibilidade aplicada objetivamente, ou seja, que reflete todos os pontos do processo material e sua unidade, leva à dialética, e é a imagem correta do eterno desenvolvimento do mundo" (1).

Nessa época, quando o pensamento de Lênin estava se desenvolvendo, um pensamento gnóstico bastante estranho e bem russo estava sendo oralmente transmitido (como fazia Sócrates) em Moscou, pelo bibliotecário da Biblioteca Pública Rumiántsev, Nikolái Fiôdorov. Seus seguidores publicaram suas principais idéias em A filosofia da causa comunitária (1903). Fiôdorov reinterpreta cosmicamente a oração de Jesus, o Pai Nosso. "Dai-nos hoje o pão de cada dia" é interpretável somente enquanto "regulagem de um fenômeno meteorológico e não como provisão de reservas ". Uma estranha aplicação coletiva do preceito do providencialismo evangélico. Outra preocupação de Fiôdorov diz respeito à salvação de nossos ancestrais, sua ressurreição e o resgate de todos os assuntos espirituais da vida. E sabemos que o pensamento de Fiôdorov teve grande influência sobre muitas pessoas na época da Revolução, por exemplo, sobre Maiakóvski e, ainda mais, sobre Andriêi Platônov.

O romance de Platônov Tchevengur, escrito em 1928 e então recusado para publicação, é um poema inspirado no providencialismo utópico. Essa extremada recusa milenarista de uma conduta humana social de caráter racional e planejado é, sob certo aspecto, uma característica do modo de ser russo. Por um lado, um enorme desprezo pela época presente e, embora conturbada por uma série de questões teológicas, uma espera mística pelo futuro. Por outro, um forte desprezo pela previsão econômica e pelo futuro econômico de cunho racional.

O filósofo francês e historiador de literatura, Georges Poulet, mostrou com acerto que, até a época do iluminismo, a preocupação com o futuro não teve qualquer privilégio especial no pensamento europeu fundado no aristotelismo. $\mathrm{O}$ principal movimento da vida era o da potencialidade para a realidade. Depois da revolução filosófica do século XVIII, isso mudou completamente. Passou a ser o da realidade para a potencialidade. O futuro torna-se o principal objeto de especulação. Mas, no Ocidente, tal preocupação está estritamente ligada aos projetos econômicos reais ou às ambições políticas.

O novo modelo de herói é Napoleão. Os heróis de Balzac são tomados pela magia do discurso napoleônico. Ao passo que, na Rússia, Raskólnikov - O jovem tosco (2) - e, em geral, todos os grandes protagonistas de Dostoiévski são antiheróis. "Possa Deus salvar a Rússia da burguesia!", escreve Herzen a seu amigo Bótkin, e este responde: "Possa Deus dar à Rússia uma burguesia". Quer dizer, os russos estão discutindo sobre o tipo de História que a Rússia pode ter: uma racional, semelhante à ocidental, e outra marxista que, em princípio, advoga o advento de uma fase burguesa como uma das etapas do decurso da história. Mas, como sabemos, o marxismo russo gradualmente aproximou-se da idéia herética de que a Rússia poderia prescindir daquela fase necessária. Prescindir, porque era muito jo- 
vem e muito jovem com relação à proporcionalidade direta com seu atraso econômico.

Em um artigo bastante interessante, Iúri Lótman contrapôs duas noções: dogovór - o contrato - e vrutchênie sebiá - a dedicação de si mesmo (a doação de si) - como dois modelos de cultura. O primeiro implica uma visão clara do futuro, da identidade dos dois parceiros; o segundo nega quaisquer parâmetros, qualquer noção de traição possível. O primeiro vem do Direito Romano, é dominante no Ocidente e está geneticamente ligado ao shamanismo, à magia; o segundo é religioso e une o ser humano a Deus. Na Rússia, afirma Lótman, não pode haver um "bom contrato". Um contrato é algo de ruim, diabólíco. "Na Rússia, o contrato é entendido como algo puramente humano, em opósição ao divino".

Lótman reconhece que o espírito do contrato apareceu na Rússia, durante o século XVIII, mas - ele acrescenta - a inteligentsia russa restaurou o espírito da "doação de si mesmo" durante o século XIX.

Outro interessante estudo de Lótman envolvendo sua compreensão do senso de futuro na Rússia diz respeito ao jogo de cartas na sociedade européia. A sociedade ocidental aprecia jogos que envolvem ação - agôn -, ou seja, a mímese da ação, ao passo que a sociedade russa prefere jogos de azar - álea - tal qual o stoss (3), em $A$ dama de espadas de Púchkin, o qual representa uma mímese da passividade humana diante do destino.

O sacrifício de si próprio, a recusa da ação racional, a frustração, quando colocada frente à frente com a industriosidade racional do Ocidente, acusada de trivialidade (pôchlost) etc. são os principais elementos da filosofia da inteligentsia russa, a qual religiosamente acredita no ateísmo, como Serguêi Bulgákov brilhantemente escreveu.

A dedicação de si próprio constituiu o arquétipo do terrorista russo, o terrorista puro, que Albert Camus chamou em sua obra de L'homme révolté. Ela é uma variante russa da "tentação pelo niilismo", como Berdiáiev diz em A idéia russa. O quiliasmo ou o milenarismo russo está, obviamente, presente no âmago do sectarismo religioso da Rússia. Tolstói, ele próprio muito atraído pelo pensamento milenarista, mostra uma característica bem marcante em Ressurreição: o príncipe Nekhliúdov, em seu trajeto para a Sibéria, encontra-se em uma balsa com um estranho vagabundo, que pertence à seita dos chamados beguny ou "voadores" (4). Os beguny recusam-se ao casamento, ao lar, a qualquer tipo de serviço estatal, até mesmo a qualquer identificação. Daí recusarem-se taxativamente a dar seus próprios nomes, quando inquiridos.

Esse extraordinário anarquista religioso intriga Tolstói-Nekhliúdov. Que tipo de futuro, ou planejamento, administrativo pode existir em um país onde uma vasta população de vagabundos encontra-se em estado nômade, mas como nômade individual e não social, e alguns deles recusam a mera noção de identidade? Sectários tiveram um papel ativo na preparação da Revolução. Seu milenarismo signifi- 
cava uma recusa a participar de qualquer projeto, qualquer reforma, qualquer tipo de vida social tolerante.

Os simbolistas russos estavam muito cientes do fenômeno milenarista na Rússia. Aleksándr Blok, estudante ainda, fizera pesquisas sobre a magia popular. Andriêi Biely estava muito interessado em todos os tipos de seitas, estudando-as no interior da Rússia com seu amigo Serguêi Soloviôv, e seu romance $A$ pomba de prata é tanto político quanto místico. Um estudante que vive em uma província rural e atrasada da Rússia, e está envolvido com uma garota da nobreza local, é literalmente absorvido pela atração mágica de uma seita de Pombas. Essa seita foi imaginada pelo poeta com base no modelo dos Khlysty (5). Toda a inteligentsia estava intoxicada com o discurso mágico dos Khlysty, especialmente depois que o poeta khlyst Kliúiev surgiu em São Petersburgo vindo do Norte e amaldiçoando a civilização moderna. A aparição de Kliúiev foi paralela à de Raspútin na política.

O filósofo marxista Bontch-Bruiévitch estudou a influência das seitas sobre a sociedade russa. Segundo ele, os Bezpopóptsy - a vertente mais radical dos Velhos Crentes - e os Khlysty foram a expressão de um comunismo primitivo. E acrescenta: "De um ponto de vista político, os Khlysty merecem toda nossa atenção, porque eles são inimigos decididos de qualquer poder (natchálstvo) (6).

Em 1912, o milenarismo floresceu em Tsarítsyn (hoje, Volgogrado) e lá apareceu uma nova figura chamada Heliódor. Ele era um monge honesto e um feroz propagandista do tchernossótienstvo (7). Tendo atacado Raspútin, foi exilado em um mosteiro e começou a pregar uma forma de anarquismo delirante. Existia um rumor de que ele seria irmão de Nicolau II (outra característica da psyché social russa é sua tendência para enganar-se e o fato de acalentar o sonho de um vínculo secreto entre o povo e o czar). Arrependeu-se publicamente por ter atacado os judeus e os intelectuais e proclamou que a Igreja e o Estado estavam nas mãos do anti-Cristo. Três mil ex-discípulos de Heliódor também renunciaram à ortodoxia. Heliódor fugiu para o exterior, voltou depois da Revolução de Fevereiro, acolheu o golpe bolchevique e foi-lhe permitido pelos bolcheviques voltar a Tsarítsyn. Na Páscoa de 1921, proclamou, à frente de uma multidão reunida na catedral, que ele abençoava o novo regime soviético. "O povo russo depôs o grande barrigudo, agora é a vez dos sacerdotes. A partir desse momento, começo uma campanha contra os popes". O propagandista ateu Iaroslávski, com o consentimento óbvio de Lênin, elogiou Heliódor.

Um dos scholars que estudaram esse estranho fenômeno, Mikhaíl Agúrski, cita previsões apocalípticas dos Velhos Crentes e sectários de vários tipos a favor dos bolcheviques. Até Vsevolôd Ivánov, em um típico texto clássico da jovem prosa soviética, Trem blindado 14-59 (Bronepóiezd 14-59), inclui a figura de um Velho Crente. Admitia-se que a maioria dos membros das seitas eram verdadeiros comunistas: dukhobôry, moloques, estundistas, testemunhas de Jeová, novos israelitas, durmanóvtchi, balabanóvtchi etc., com mais de dez milhões de adeptos, sem incluir os Velhos Crentes. Finalmente, Heliódor foi expulso em 1922, mas seus se- 
guidores foram definitivamente aniquilados apenas em 1938. Os marxistas pensavam que esses movimentos milenaristas eram a manifestação do comunismo primitivo, do comunismo anarquista e que, guiados pelos comunistas verdadeiramente conscientes, poderiam ser uma ajuda poderosa. $\mathrm{O}$ exemplo do movimento anabatista camponês, na Alemanha do século XVI, como um tipo de prelúdio comunista, foi utilizado por Engels e pelo próprio Lênin em seu artigo $A$ respeito do Estado ( $O$ gossudárstve).

Um velho menchevique chamado Vólski deixou-nos dois livros bastante significativos que dizem respeito ao tema da relação entre o milenarismo religioso e o bolchevismo. Vólski, na década de 1900, tentou converter os poetas simbolistas ao marxismo. Ele tinha alguma influência sobre Andriêi Biely. Ivanóv-Razúmnik, um social-revolucionário bem conhecido como autor da História do pensamento social russo, converteu seus amigos Blok, Biely, Riêmizov e Essiênin às posições populistas sob os auspícios de sua revista Skify (Os Citas). Sem entrar em grandes detalhes, pode-se dizer que uma parte da inteligentsia russa acolheu os eventos de 1917 como uma Revolução do espírito, ou seja, um profundo e coletivo sismo psíquico no âmago da alma do povo. Eles interpretaram os eventos políticos como uma expressão daquele evento religioso e a vitória do bolchevismo como algo de superficial, um epifenômeno. O poema de Blok, Os doze, foi uma das mais importantes expressões dessa crença em uma revolução espiritual simbolizada pela figura de Jesus Cristo andando pelas ruas da revolucionária São Petersburgo. Em seu famoso discurso, proferido na Academia Filosófica Livre (Volfila), Blok deu uma interpretação cósmica à revolução. Tal discurso é intitulado $A$ desintegração do humanismo. A tese de Blok era que a Revolução não seria somente um evento histórico russo, mas um evento de significação universal, em que o humanismo europeu viria a ser condenado.

Essa interpretação pessimista e lírica da Revolução Russa - semelhante às teses de Spengler em $O$ declínio do Ocidente (embora o livro de Spengler não tivesse sido publicado ainda) - não era cínica, como Merejkóvski e outros pensavam, mas uma expressão de desespero universal. Entre a escrita exaltada e febril de $O s$ doze e $O$ declínio do humanismo, Blok e os poetas e filósofos do movimento dos citas tiveram tempo suficiente para concluir que o bolchevismo era uma falsa revolução do espírito. A detenção, por dois dias, de todo o grupo de Ivanóv Razúmnik (incluindo Blok) pela Tcheká foi uma experiência de grande significância para eles. A Associação Filosófica Livre (Volfila), que teve curta existência, foi uma tentativa isolada, e condenada ao fracasso, da experiência de liberdade de pensamento no início do poder soviético. A associação, tal como foi descrita nas memórias de Aaron Steiner (8), organizou palestras sobre Campanella e a utopia européia. Ligar a revolução bolchevique ao pensamento utópico europeu em geral era, obviamente, antimarxista. Significava borrar a distinção entre o materialismo histórico e o dialético...

Já mencionamos o papel das seitas na consolidação do golpe bolchevique. Falando mais genericamente sobre religião, a aversão à ortodoxia oficial era bas- 
tante difundida e suficiente para explicar o ateísmo oficial, o vandalismo dessa época e a criação de uma igreja pró-soviete, o então chamado movimento Igreja Viva, encabeçado por Vyediênski, que era o habitual opositor de Lunatchárski, nos debates públicos daqueles tempos. Um jovem adepto da herética igreja de Vyediênski foi Anatóli Krasnóv Levítin, um futuro dissidente, que na década de 80 emigrou para a Suíça, vindo a morrer em Lucerna após ter escrito uma enorme mas não muito científica história sobre a Igreja Viva. Mas, Anatóli Krasnóv-Levítin é um típico exemplo de atitude bem russa. Em seu livro, meio autobiográfico e meio fantástico, Uma estrela chamada Mair (1989), descreve a si próprio como um cristão, socialista e russo. Pode-se acrescentar a isso, anarquista, porque sua aversão por qualquer tipo de poder é extremada. "Um interessante conglomerado de socialismo e cristianismo", escreve ele. Na política, quando jovem, sentiu alguma simpatia pelo populismo, ou seja, pelos S.R. ou socialistas revolucionários. Tal aversão pelo poder, por qualquer poder, incluindo o eclesiástico, provavelmente é uma das raízes da Revolução Russa. Isso foi explorado por Lênin, que era ateu, obviamente, mas bastante consciente de que o ateísmo russo era um tipo de crença e, mais ainda, uma crença fanática.

Essa religião ateísta, com seus elementos de anarquismo e histeria social, foi analisada por Serguêi Bulgákov, depois de sua mudança do marxismo para o idealismo. Bulgákov é um importante pensador filosófico teológico e também econômico e social. Seu diálogo, escrito em 1918, No banquete dos deuses - pró e contra, discute problemas filosóficos, tal como Soloviôv tinha feito conforme a tradição platônica e, em particular, o papel do socialismo e do cristianismo na História da Rússia. O texto de Bulgákov coloca a seguinte questão: como pôde um milênio de cristianismo submisso ser repentinamente transformado em um orgíaco massacre de sacerdotes? Por exemplo, em seu texto, um general diz: "Até a Igreja tornou-se bolchevique", e outra pessoa refuta: "A onda revolucionária atingiu as paredes da Igreja". Ao longo de todo o diálogo, com suas oposições (Sagrada Rússia - lei do Ocidente, Rússia demonizada - resistência espiritual, traição da inteligentsia santificação da inteligência) é, de fato, o velho paradoxo eslavófilo que está obviamente em ação: quanto mais a Rússia parece impura, mais pura ela é em sua essência... Chamei a isso de paradigma socrático-eslavófilo: Sócrates era feio, mas em seu âmago era esplêndido.

Problemas morais estavam em jogo e só podem explicar de maneira parcial a Revolução de 1917. Meu ex-mestre na Sorbonne, Pierre Pascal, que adotou o comunismo em 1918 como quem entra para um mosteiro e ficou na Rússia por 70 anos, era um católico bolchevique, um tipo de hapax, um fenômeno raro; entretanto, seu sonho da união de comunismo e cristianismo não era tão raro assim. Em um de seus últimos textos, fornece a explicação moral para a revolução bolchevique. A Rússia, diz ele, desenvolveu-se tremendamente; o analfabetismo foi quase erradicado, uma nova e grande inteligentsia de classe média estava se formando, a nova classe que Lênin denominou "a nova democracia". Mas, diz Pascal, a evolução moral tinha ficado para trás. As velhas formalidades sociais, tal como o modo 
de tratamento dado às pessoas importantes (vossa excelência, entre outros), por exemplo, era agora sentido como algo humilhante e insuportável. Pascal sublinha que ele próprio e outros mais se tornaram bolcheviques sem ter qualquer noção sobre o marxismo. O principal alvo da revolução era moral e social. Igualdade entre as pessoas, destruição do Estado e abolição do exército. O derrotismo, assim como a aversão ao militarismo, era um ponto fundamental. "Um paraíso em formação", tal é sua expressão. As revoluções moral e social, supostamente, permitiriam o surgimento de um "novo ser humano". Na representação de Pascal, esse "trabalho hercúleo" forjaria um novo homem comunista, com uma crença evangélica de tipo inconsciente.

O ideal de um novo ser humano, comum a Pascal, aos poetas do Proletcult, a futuristas como Maiakóvski ou Khlêbnikov, tinha desempenhado um grande papel. Não é somente um típico ideal utópico, mas vem diretamente do Novo Testamento e das epístolas de São Paulo. A Revolução Russa fez vasto uso dos conceitos e fórmulas paulinas. Isso pode ser analisado e demonstrado com os exemplos de Essiênin, Maiakóvski e muitos poetas proletários, como Gástiev. A criação daquele Novo Ser Humano, que une a Revolução Russa a todos os projetos utópicos anteriores, como a República dos Pobres, em Munster, no século XV, ou a criação de um Novo Mundo pelos peregrinos do Mayflower, tinha uma base religiosa tão forte que Pascal, quando vai à Catedral da Dormição na Páscoa de 1918 e vê o Patriarca Tikhón celebrando a liturgia, enche-se de um êxtase místico. A noção de tempo que está implícita nessa experiência mística da Revolução está, obviamente, despojada de qualquer vestígio de reformismo. Reformismo e parlamentarismo são abominados por Pascal e seus camaradas (que esplêndida palavra!, explica ele).

A aguda aversão de Pascal pelo parlamentarismo explica sua aprovação ao fechamento da Assembléia Constituinte. "O czarismo russo" - ele acrescenta em uma pequena autobiografia - "parecia-me, à distância, mais belo que qualquer parlamento ocidental". Seu menosprezo pela tagarelice parlamentar (govorílnia, diria Lênin) tem origem em seu menosprezo pela burguesia, um sentimento bem desenvolvido no pensamento social russo, e que permeia, por exemplo, toda a vida e o trabalho de Alexander Herzen.

Deveríamos afirmar, como o fez o historiador Bagno em uma coletânea de ensaios sobre as utopias russas, publicada em 1995 em São Petersburgo, que "a consciência russa é predominantemente utópica" e, conseqüentemente, a Revolução Russa não é tanto o resultado de parâmetros sociais e econômicos, quanto a translação de uma psyché utópica a uma linguagem da história? O utopismo foi de fato uma componente significativa no pensamento de Tolstói, tão destrutiva para o Velho Regime Russo. O utopismo foi predominante dentro da geração dos simbolistas russos, mais conhecida pela figura do poeta Aleksándr Blok. O utopismo predominou entre as massas que estavam ativas na capital russa em 1917. Como Siniávski escreveu, o bolchevismo explorou a aura onírica de seu próprio nome: bolche significa mais. Sabemos, por essa razão, que o Partido Democrata Social dividiu-se, no ano de 1904, em bolcheviques e mencheviques. Mas as massas não 
sabiam e pensavam que os bolcheviques lhes dariam bolche, isto é, mais. E quem não quer mais? Até Soljenítsin, em sua Roca vermelha ataca mais ferozmente os reformistas - como Miliúkov - do que os bolcheviques. Pode-se até dizer que a figura de Chliápnikov, um bolchevique de Murom nascido em uma família de Velhos Crentes, lhe é bastante simpática .

A ambivalência da interpretação religiosa da Revolução Bolchevique vê-se melhor em alguns trabalhos literários, como o romance Tchevengur de Andriêi Platônov. A parábola sobre o comunismo, à procura do qual estão todos os heróis de Tchevengur, recorre a vários mitos: o do povo judeu em busca da Terra Prometida, o da eucaristia, o de sonhos fanáticos simbolizados por Kopiônkin. Seu próprio nome evoca a figura de Dom Quixote (com seu kopiô ou lança). Tchevengur é um Dom Quixote sui generis, com seu estilo meio cômico, meio místico. Os vagabundos espirituais que vagueiam em um simbólico espaço vazio (a estepe russa) são, ao mesmo tempo, crentes fanáticos no comunismo e míseros idiotas .

Em um ensaio sobre os três porquês da Revolução Russa, Richard Pipes demonstrou que, de acordo com ele, e contrariamente a muitas opiniões tradicionais:

- a queda do regime czarista não era inevitável;

- a vinda ao poder de Lênin foi um resultado do acaso;

- a sucessão de Lênin por Stálin foi, ao contrário, uma conseqüência lógica.

Pipes fala dos fantásticos planos de Lênin, que eram caracterizados por uma obstinação fanática. Em certo sentido, a própria natureza fantástica do plano de Lênin deu-lhe uma força inesperada: as pessoas estavam convencidas de que aquilo não poderia durar muito tempo e se lhe opuseram demasiado fracamente.

Os anos de 1920 e 1921 foram marcados por rebeliões maciças, mas já era muito tarde. O desesperado S.O.S. enviado pelos marinheiros do Kronstadt era o apelo do proletariado do mundo inteiro contra a tirania bolchevique. Mas já era tarde demais. O exército de Trótski já estava fanatizado e pronto para a ação. Operar com as noções místicas de revolução e contra-revolução já era uma prática corrente do bolchevismo e o Kronstadt foi uma das primeiras vítimas daquela extraordinária, cínica e ao mesmo tempo eficiente política.

A época revolucionária tornou-se uma época enganadora, de enredo enganador e de guerras sociais enganadoras. $\mathrm{O}$ romance soviético tornou-se a história de um conflito entre aspectos positivos e outros mais positivos de uma pseudorealidade. Aí, veio o tempo ritual da estagnação. Parecia não haver mais futuro, tudo estava ritualizado. De uma comemoração a outra, somente pequenas diferenças na hierarquia indicaram aos especialistas as mudanças clandestinas que estavam ocorrendo. A História estava, sob certo aspecto, terminada, e o sociólogo e satírico Aleksándr Zinôviev podia gabar-se de calcular, com precisão, que o futuro do império comunista duraria os próximos mil anos. Seria o grande milênio pelo qual a humanidade estava esperando. 
Mas, de repente, o império comunista implodiu. A História tomou de assalto o palco da Rússia. O resultado foi a completa imprevisibilidade do futuro, a vida passou a ser limitada à sobrevivência do dia a dia. Tal fato significa que a Rússia não é mais uma nação utópica? Que os Kopiônkins desapareceram para sempre? A História decidirá. Meu prognóstico é: não, a utopia não pode ser desenraizada definitivamente. Mas parece ainda muito cedo, enquanto a Rússia está se transformando rapidamente, tornando-se meio cínica e meio reformista, repensando penosamente seu passado e ressuscitando as velhas tradições das festas populares, ou gulyánie, como vimos nas comemorações de Moscou. Mesmo assim, muitos elementos da realidade atual podem ser explicados somente pelos resquícios da utopia russa. O melhor exemplo é a persistente recusa de permitir-se a privatização da terra. A Rússia não possui uma lei sobre a propriedade das terras. $\mathrm{O}$ velho tabu - a terra pertence a Deus e não ao homem - parece ainda estar vigorando.

Notas

1 Lênin, Cadernos Filosóficos.

2 "Em estado natural" (nota da revisora).

3 Stoss; do al. "golpe, choque". Em $A$ dama de espadas de Púchkin, é usado o neologismo stossovat, com o significado de "embaralhar as cartas" (nota da revisora).

4 "Corredores", segundo nota da revisora.

5 Klysty; de khlyst, "chicote", indicando a seita dos flagelantes russos (nota da revisora).

6 Citado de acordo com Mikhaíl Agúrski: "L’aspect millenariste de la révolution bolchevique". In: CMRS, v. XXIX, 314, p. 501.

7 Tchernossotiêntsi: membros de uma seita de extrema direita russa, dita dos cem pretos, criada em 1905 pela polícia czarista e por grupos monarquistas para combater movimentos considerados revolucionários. Foi extinta em fevereiro de 1917 (nota da revisora).

$8 \mathrm{Eu}$ as editei e publiquei em 1991. A. Steinbert. Druziá moikh ránnikh liêt: 19111928. Paris, 1991.

Georges Nivat é professor na Universidade de Genebra e diretor do Departamento de Línguas Mediterrâneas, Eslavas e Orientais.

Tradução de Euro de Barros Couto Jr. Revisão de Aurora F. Bernardini. O original em inglês - Millenarist elements in the russian revolution - encontra-se à disposição do leitor no IEA-USP para eventual consulta. 